\title{
Members of the Arabidopsis WRKY Group III Transcription Factors Are Part of Different Plant Defense Signaling Pathways
}

\author{
Monika Kalde, Meike Barth, Imre E. Somssich, and Bernadette Lippok \\ Max-Planck-Institut für Züchtungsforschung, Abteilung Molekulare Phytopathologie, Carl-von-Linné Weg 10, D-50829 \\ Köln, Germany
}

Submitted 2 October 2002. Accepted 11 December 2002.

\begin{abstract}
WRKY proteins are a large group of transcription factors restricted to the plant kingdom. In Arabidopsis thaliana, the gene family consists of $\mathbf{7 4}$ members. Here, we analyzed the expression of all 13 members of one main WRKY subgroup and found that the majority are responsive both to pathogen infection and to salicylic acid. Temporal expression studies during compatible, incompatible, and nonhost interactions and employing plant defense-signaling mutants allowed us to define four distinct WRKY subsets responding to different signaling queues along defense pathways. These subsets did not reflect phylogenetic relationships. Promoter studies of one member, AtWRKY54, using a reporter gene construct in transgenic Arabidopsis plants, revealed that regulatory regions mediating pathogen and $\mathrm{SA}$ inducibility are clearly separable. In an AtWRKY54 knockout line, resistance to Peronospora parasitica was not compromised, but the transient expression kinetics of several WRKY genes was affected, suggesting both the existence of functional redundancy and intense cross-talk between signaling networks.
\end{abstract}

Additional keywords: ascomycete Blumeria graminis, nahG, oomycete, pad4, RPP2, RPP4.

The mechanisms protecting the majority of plants against most potential microbial pathogens are highly regulated processes. An important step in their regulation is the transcriptional activation or repression of numerous defenserelated genes by distinct transcription factors. Previous studies have identified several transcription factors that are involved in plant defense, including members of plant-specific families like NAC proteins (Ren et al. 2000), the group of ethyleneresponsive element-binding proteins ( $\mathrm{Gu}$ et al. 1992), and WRKY proteins (Eulgem et al. 2000).

The family of WRKY proteins is becoming more and more a subject of interest. Members of this family have been identified in numerous plant species, e. g., wild oat (Rushton et al. 1995), parsley (Rushton et al. 1996), sweet potato (Ishiguro and Nakamura 1994), potato (Dellagi et al. 2000), tobacco (Wang et al. 1998), rice (Kim et al. 2000), winter bittersweet nightshade (Huang and Duman 2002), orchardgrass (Alexandrova and Conger 2002), desert legume (Pnueli et al. 2002), and Arabidopsis thaliana (de Pater et al. 1996). WRKY

Corresponding author: I. E. Somssich; Telephone: +49-221-5062-310; Fax: +49-221-5062-313; E-mail: somssich@ mpiz-koeln.mpg.de. proteins have been shown to be strongly involved in the alteration of gene expression in response to microbial pathogens, pathogen elicitors, and viruses and upon treatment with signaling substances such as salicylic acid (SA) (Asai et al. 2002; Chen and Chen 2002; Dellagi et al. 2000; Eulgem et al. 1999; Yoda et al. 2002).

A common feature of all WRKY proteins is the WRKY domain, a highly conserved stretch of about 60 amino acids. Each WRKY domain contains a C-terminal located novel zinc finger and the strictly conserved amino acid sequence WRKYGQK at its N-terminus. This sequence is required for proper folding of the zinc finger and, therefore, is coresponsible for DNA binding (Maeo et al. 2001). The WRKY domain binds specifically to various $\mathrm{W}$ box elements, all containing a TGAC core sequence (de Pater et al. 1996; Rushton et al. 1995, 1996; Wang et al. 1998). W boxes have been identified in the promoters of many defense-related genes, including the well studied $P R$ genes (Maleck et al. 2000; Rushton et al. 1996) and within WRKY gene promoters themselves, thereby suggesting that WRKY factors can regulate their own expression (Eulgem et al. 1999). Recently, putative target genes for WRKY factors, encoding receptor-like kinases (Asai et al. 2002; Du and Chen 2000; Ohtake et al. 2000; Robatzek and Somssich 2002) and an ankyrin-repeat protein (NPR1) (Yu et al. 2001), have been identified. However, the physiological function of most of the WRKY factors identified so far remains unclear.

In Arabidopsis, 74 members of the WRKY family are present (AGI 2000). These factors have been arranged in three distinct groups depending on the number and type of their WRKY domains (Eulgem et al. 2000). In this study, the transcriptional regulation of WRKY group III, consisting of 13 members, was analyzed and compared under different conditions for the first time. Group III differs from groups I and II in its altered $\mathrm{C} 2-\mathrm{HC}$ zinc finger motif C-X7-C-X23-H$\mathrm{X}-\mathrm{C}$. The results presented here show that the transcriptional activation upon pathogen attack and treatment with SA is a common feature of most of the group III WRKY genes. Furthermore, most of these genes are expressed during both nonhost and $R$ gene-dependent resistance. The analysis of mutants lacking key components of plant defense pathways showed that even closely related WRKY members display strong differences in their expression patterns and are most likely involved in distinct signaling pathways. A detailed analysis of one member, AtWRKY54, revealed that different promoter regions are responsible for its induction after treatment with SA or upon inoculation with pathogens, respectively. 


\section{RESULTS}

Phylogenetic relationship of group III WRKY type factors.

Originally, 14 out of the 74 Arabidopsis WRKY factors were classified as group III members (Table 1). However, AtWRKY52 (also designated RRS1), proved to be rather exceptional. Not only does it have an altered zinc finger motif (C2-H2), but in addition, it contains other domains such as leucine-rich repeats and a motif with similarity to the signaling domain of the Drosophila Toll protein. Both types of motifs are known from $R$ gene products but are usually not present in other WRKY factors, with the exception of AtWRKY16 (Deslandes et al. 2002). Because it does not fit neatly into group III but might represent a novel group within the Arabidopsis WRKY family, AtWRKY52 was not a subject in this study. A phylogenetic tree, based on amino acids of their highly conserved WRKY domains, shows that the remaining 13 proteins can be further subdivided into two subgroups (Fig. 1), group IIIa (AtWRKY38, AtWRKY62, AtWRKY63, AtWRKY64, AtWRKY66, and AtWRKY67) and IIIb (AtWRKY30, AtWRKY41, AtWRKY46, AtWRKY53, AtWRKY54, AtWRKY55, and AtWRKY70).

Although WRKY proteins do not share extended sequence homologies outside of the WRKY domain, some members contain other conserved amino acid patterns (Eulgem et al. 2000). The analysis for such conserved regions within the amino acid sequences of group III proteins was performed using the MEME and MAST program versions 3.0 (Bailey and Elkan 1994; Bailey and Gribskov 1998). Only members of group IIIa share a highly conserved region of about 50 amino acids located N-terminal to the WRKY domain. Furthermore, we found a second conserved sequence of 30 amino acids that is located C-terminal to the WRKY domain. This sequence is only present in AtWRKY63, AtWRKY64, AtWRKY66, and AtWRKY67, which group on a group IIIa sub-branch in the phylogenetic tree (Fig. 1). No putative functions can be assigned to these regions. Since both regions are strongly charged and acidic ( $\mathrm{pI}$ of 4.35 and 3.65, respectively), they may represent transactivation domains. A BLASTP search using these sequences revealed that they are not present in any other known proteins. These results indicate that the relatedness of different WRKY proteins within group III is reflected by both their highly conserved WRKY domain and other conserved regions outside of this domain.

Table 1. Genomic loci and protein accession numbers of the original 14 group III WRKY type proteins from Arabidopsis thaliana

\begin{tabular}{|c|c|c|}
\hline Protein name & Genomic locus & EMBL accession numbers \\
\hline AtWRKY30 & At5g24110 & AAK96196 \\
\hline AtWRKY38 & At5g 22570 & AAL35288 \\
\hline AtWRKY41 & At4g 11070 & AAL35289 \\
\hline AtWRKY46 & At2g46400 & AAK96020 \\
\hline $\begin{array}{l}\text { AtWRKY52 } \\
\text { (RRS1) }\end{array}$ & At $5 \mathrm{~g} 45270^{\mathrm{a}}$ & \\
\hline AtWRKY53 & At4g23810 & AAK28442 \\
\hline AtWRKY54 & At $2 \mathrm{~g} 40750$ & AAL29430 \\
\hline AtWRKY55 & At2g40740 & AAD32805 \\
\hline AtWRKY62 & At5g01900 & AAK28310 \\
\hline AtWRKY63 & At1g66600 & AAL50782 \\
\hline AtWRKY64 & At1g66560 & AAL61860 \\
\hline AtWRKY66 & At1g80590 & AAF27132 \\
\hline AtWRKY67 & Attg $66550^{\mathrm{a}}$ & AAL13043 \\
\hline AtWRKY70 & At3g56400 & AAL13046 \\
\hline \multicolumn{3}{|c|}{$\begin{array}{l}\text { The predicted open reading frames of these accessions do no } \\
\text { correspond to the experimentally determined sequences. The correcte } \\
\text { sequence for AtWRKY52 has been deposited in the GenBank databas } \\
\text { (accession numbers AX103688, AX103684, AX103691, an } \\
\text { AX103687). }\end{array}$} \\
\hline
\end{tabular}

In Figures 2 through 6, WRKY factors that show a similar position in the phylogenetic tree are organized together to allow a better comparison of the transcript accumulation among structurally related family members.

\section{Expression of group III WRKY factors after treatment with SA.}

To initiate studies concerning the physiological functions of the different members of group III, we characterized the SAmediated accumulation of their mRNA transcripts. SA functions as signaling substance, and its accumulation plays a central role in the activation of defense reactions leading to plant disease resistance (Delaney et al. 1994). Two-week-old plants were sprayed with $5 \mathrm{mM}$ sodium salicylate, and the transcript abundance of the chosen WRKY factors was analyzed by reverse transcription-polymerase chain reaction (RT-PCR) (Fig. 2A). Most of the transcripts analyzed undergo a strong accumulation within the first $4 \mathrm{~h}$ of treatment. Particularly, AtWRKY38, AtWRKY46, AtWRKY53, AtWRKY54, AtWRKY62, AtWRKY64, AtWRKY67, and AtWRKY70 show a strong increase in expression within the first $2 \mathrm{~h}$. Only AtWRKY30 and AtWRKY55 are not clearly induced after spraying with SA. Both are members of subgroup IIIb, albeit only distantly related, according to our phylogenetic analysis. This result indicates that most members of WRKY group III may have a related, SA-dependent function in signal transduction. The members differing in this feature do not share extended sequence similarity.

Our results were basically confirmed by Northern analysis (Fig. 2B), with two exceptions, namely, AtWRKY66 and AtWRKY41. Most likely the lower detection sensitivity of RNA blot analysis compared to RT-PCR is the cause of this discrepancy. Nevertheless, the similarity between the results derived from both methods and the higher sensitivity of RT-PCR favored the use of this method for subsequent analyses.

\section{Expression of group III WRKY factors} after inoculation with different pathogens.

We next analyzed the accumulation of group III WRKY transcripts upon inoculation with different microbes. We tested both compatible and incompatible interactions with the oomy-

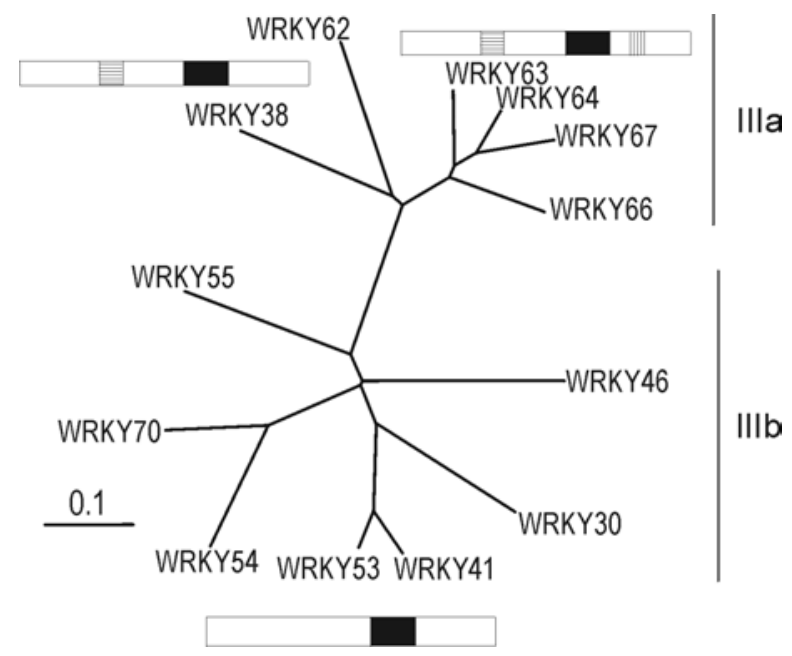

Fig. 1. Phylogenetic analysis of the Arabidopsis WRKY group III. Amino acid sequences from the WRKY domains were aligned using CLUSTALW (Thompson et al. 1994). The diagram shows an unrooted tree constructed with the TREEVIEW program (Page 1996). Schematic representations of typical members of each subgroup are shown above and underneath the tree. Black boxes indicate the WRKY domain; boxes with stripes represent conserved acidic domains identified using MEME and MAST (Back and Chappell 1996; Bailey and Elkan 1994; Bailey and Gribskov 1998). 
cete Peronospora parasitica, as well as nonhost interaction with the ascomycete Blumeria graminis f. sp. hordei, a natural pathogen of grasses (Fig. 3). The ecotype Columbia (Col-0) is resistant to $P$. parasitica isolates Cala2 and Emoy2 because of the race-specific resistance $(R)$ genes $R P P 2$ or $R P P 4$, respectively. Recently, it has been demonstrated that these two $R$ genes transduce resistance responses via different signaling pathways (McDowell et al. 2000). After inoculation of plants with these isolates, neither hyphal growth nor host cell death is visible $72 \mathrm{~h}$ after inoculation (Fig. 3A and C). The ecotype Landsberg erecta (Ler-1) lacks the RPP2 gene and is thus susceptible to $P$. parasitica Cala2, which forms an extended intercellular mycelium in rosette leaves (Fig. 3B). By using the nonhost pathogen $B$. graminis f. sp. hordei, a different type of interaction was analyzed. Nonhost resistance is thought to function independently of the occurrence of major $R$ genes but shares with $R$ gene pathways certain signaling components (Heath 2000). B. graminis f. sp. hordei fails consistently to infect cells of Arabidopsis. Although extracellular infection structures, including appressoria, are formed within $24 \mathrm{~h}$ postspore inoculation on leaves, germinated spores almost quantitatively fail to grow invasively, even after $72 \mathrm{~h}$ (Fig. 3D).

Gene expression analyses revealed that most of the investigated genes are induced after inoculation with the described microbes (Fig. 4). Data presented here and for following figures were derived from two independent experiments. During $R P P 2$-mediated resistance, the analyzed transcripts accumulate early, in general not later than 4 to $6 \mathrm{~h}$ postinoculation (Fig. 4A). At this time, no signs of pathogenic growth, even in the compatible interactions, are visible (data not shown). In susceptible Ler-1 plants however, the majority of analyzed WRKY genes are activated later than $6 \mathrm{~h}$ postinoculation (Fig. 4B). Expression analysis of WRKY group III genes during RPP4mediated resistance also showed delayed induction kinetics for most of the analyzed genes compared with RPP2-mediated resistance (Fig. 4C). These findings indicate that the early expression of the majority of WRKY group III genes is specific for $R P P 2$-mediated resistance. The delayed induction in the compatible interaction and after inoculation with $P$. parasitica Emoy2 may be due to other defense signals that do not depend on the recognition of an avirulence gene product. During nonhost resistance of Col-0 against $B$. graminis $\mathrm{f}$. sp. hordei, most of the tested WRKY genes are induced within $24 \mathrm{~h}$ postinoculation (Fig. 4D) and thus expressed simultaneously with the differentiation of extracellular infection structures on the leaf surface.

A closer look at the expression pattern of single WRKY genes in the different interactions reveals unexpected differences. Several expression patterns can be discriminated, suggesting distinct expression fingerprints for each interaction. Only one gene, AtWRKY54, is induced with similar kinetics during both $R P P 2$ - and $R P P 4$-dependent interactions, suggesting that the encoded protein is shared by both $R$ gene-triggered signaling cascades. The AtWRKY54 protein exhibits $43 \%$ amino acid identity to its closest putative relative AtWRKY70. Their WRKY domains show over $80 \%$ identity. Nevertheless, the induction of AtWRKY70 is delayed during RPP4-mediated resistance. Another gene, AtWRKY62, is induced after inoculation with $P$. parasitica, but not during nonhost resistance. However, the WRKY factor with highest similarity to AtWRKY62 is AtWRKY38, which is clearly induced within $24 \mathrm{~h}$ postinoculation with $B$. graminis f. sp. hordei. Only one of the analyzed genes, AtWRKY64, is not expressed after inoculation with any of the pathogens tested but shows a clear induction after treatment with SA. Closely related to AtWRKY64 are AtWRKY63 and AtWRKY67, whose genes are strongly induced during interaction with $P$. parasitica. The only genes that are expressed consistently at $2 \mathrm{~h}$ postinoculation are AtWRKY53 and $A t W R K Y 30$, which are both expressed in control plants, too, and thus may be responding to other factors (e.g., diurnal rhythms) than the inoculation with pathogens.

Besides the $R$ genes themselves, additional components of pathways that lead to $R$-gene dependent resistance have been previously identified (Glazebrook 2001). For RPP2- and RPP4mediated resistance, the PAD4 protein is required; pad4-1
A

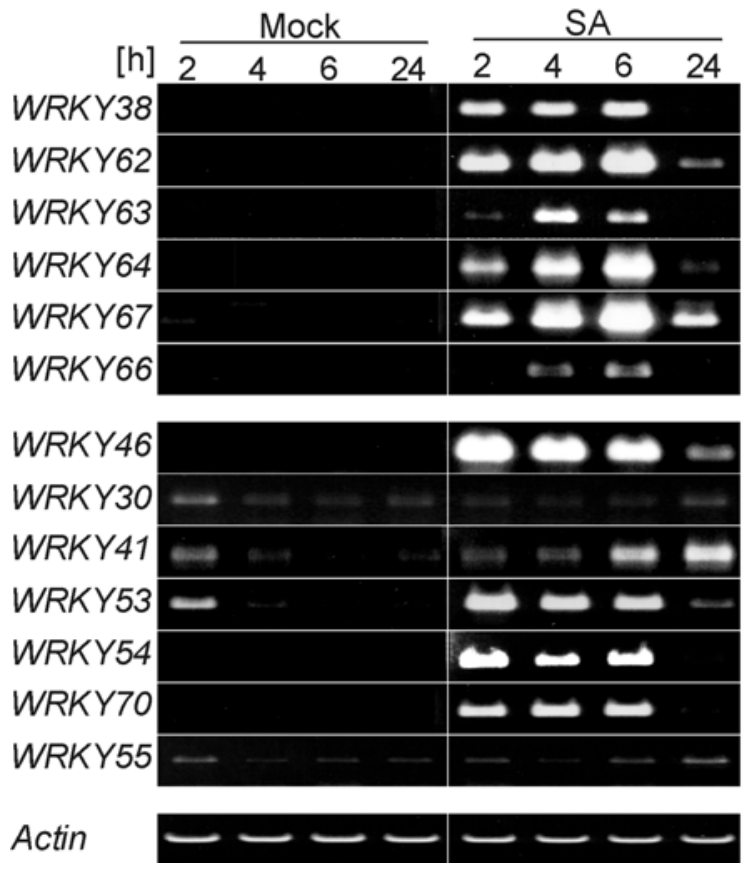

B

\begin{tabular}{|c|c|c|c|c|c|c|c|c|}
\hline & & & ck & & & SA & & \\
\hline [h] & 2 & 4 & 6 & 24 & 2 & 4 & 6 & 24 \\
\hline WRKYЗ8 & & & & & $\Leftrightarrow$ & & & 6 \\
\hline /RKY62 & +2 & & & & & & & 6 \\
\hline WRKY63 & & & $e^{3}$ & $y$ & & 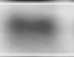 & $=$ & \\
\hline WRKY 64 & 2 & 5 & & & & $=$ & $=$ & \\
\hline WRKY 67 & 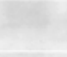 & 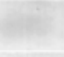 & & & -1 & $=$ & 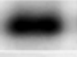 & - \\
\hline WRKY66 & & & & & & & & \\
\hline WRKY46 & 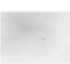 & & & & & & & \\
\hline WRKYЗО & $2=$ & $*^{*}$ & 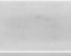 & 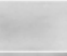 & & & & . \\
\hline WRKY41 & 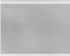 & & & 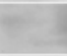 & & & & \\
\hline WRKY53 & - & $=$ & - & 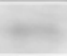 & - & - & - & - \\
\hline WRKY54 & 2 & & & & & & - & $=$ \\
\hline WRKY70 & 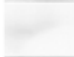 & & & & & & 0 & $=$ \\
\hline WRKY55 & & & & 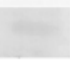 & & & & \\
\hline
\end{tabular}

Fig. 2. Time course analysis of WRKY group III gene expression upon treatment with salicylic acid (SA). A, Reverse transcription-polymerase chain reaction (RT-PCR). Primers for actin were used as control. B, RNA blot analysis. Asterisks indicate an exposure time of more than 24 h. Ethidium bromide staining of rRNA is shown as loading control. 
mutant plants show clearly diminished resistance against $P$. parasitica Cala2 (Glazebrook et al. 1997). Accumulation of SA is required for RPP4-mediated but is negligible for the RPP2mediated resistance against $P$. parasitica Cala2 (McDowell et al. 2000). Transgenic plants, expressing a sequence coding for a SA-degrading bacterial salicylate hydroxylase $(n a h G)$ from Pseudomonas putida, show very weak effects on the growth of P. parasitica Cala2 (McDowell et al. 2000). To ascertain if the lack of PAD4 or SA effects the expression of $W R K Y$ genes, we inoculated $n a h G$ transgenic plants as well as pad4-1 mutant plants with $P$. parasitica Cala2 (Fig. 5). In pad4-1 plants, transcript accumulation of $W R K Y$ genes is generally delayed (exceptions being AtWRKY30, AtWRKY53, and AtWRKY55) (Fig. 5A). In nahG transgenic plants some of the analyzed genes are not affected in their timely induction (Fig. 5B). These include the genes AtWRKY70, 30, 41, 53, and 55. Other genes show a strongly delayed or even no detectable induction during the first 3 days postinoculation (AtWRKY38, AtWRKY54, AtWRKY62, AtWRKY63, and AtWRKY66).

PAD4, a lipase-like protein, is not only responsible for the synthesis of the phytoalexin camalexin in response to infection with Pseudomonas syringae pv. maculicola ES4326 (Glazebrook and Ausubel 1994) but, perhaps more importantly, is also a general component of the SA signal transduction cascade leading to systemic acquired resistance in plants. PAD4 is required for the accumulation of SA and thus acts upstream of SA accumulation in regulating defense response expression (Zhou et al. 1998). We tested whether the SA responsiveness of WRKY group III genes in wild-type plants (Fig. 2A) depends on a functional PAD4 protein by treatment of pad4-1 plants with SA. As shown in Figure 5C, there is no difference between wild-type and mutant plants in the expression pattern of most of the tested $W R K Y$ genes, with the notable exception of AtWRKY64, whose expression is not induced by SA in pad4-1 mutants. Thus, although the SA responsiveness generally occurs independently of PAD4, consistent with the proposed upstream position of PAD4 relative to SA accumulation, high SA levels must act together with a PAD4-derived signal to stimulate AtWRKY64 expression. Similar to the wild-type situation, most analyzed

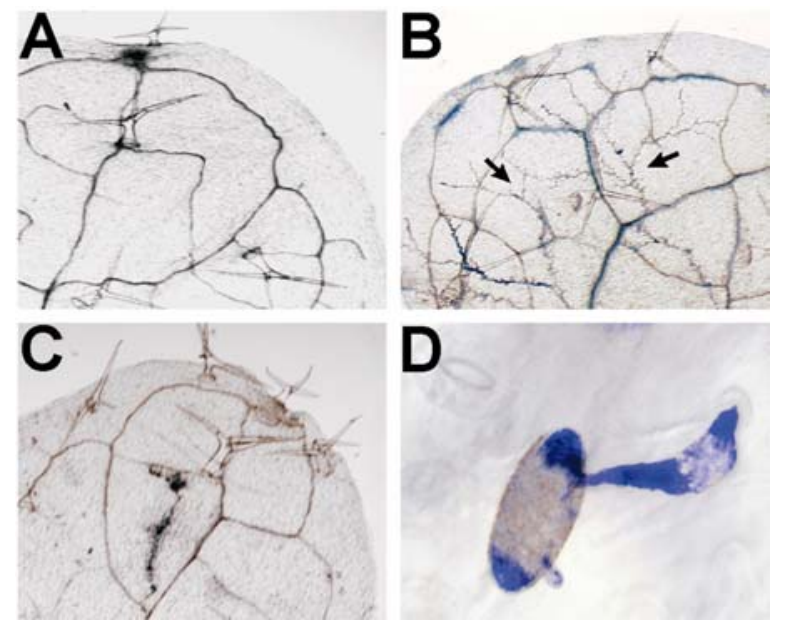

Fig. 3. Plant-microbe interactions chosen for expression analysis of the Arabidopsis group III WRKY family. A, Incompatible interaction of Columbia (Col-0) and Peronospora parasitica Cala2; B, Compatible interaction of Landsberg erecta (Ler-1) and P. parasitica Cala2. Arrows show hyphal growth of Peronospora parasitica. C, Incompatible interaction of Col-0 and $P$. parasitica Emoy2; D, Incompatible interaction of Col- 0 and the nonhost pathogen Blumeria graminis $\mathrm{f}$. $\mathrm{sp}$. hordei. Cell wall of B. graminis f. sp. hordei is stained with Coomassie three days after inoculation. A, B, and C, show cotyledons stained with Trypan blue to detect hyphal growth three days after inoculation. genes are clearly expressed transiently with a decreased transcript level after $24 \mathrm{~h}$. However, expression of AtWRKY66 is not transient in the pad4-1 mutant, and expression of AtWRKY41 is hardly detectable.

\section{Role of AtWRKY54 during plant defense.}

The only gene that is expressed with nearly the same temporal kinetics in the two tested $R$ gene-specified interactions is AtWRKY54. Therefore, AtWRKY54 may be a component of a signaling cascade, integrating both $R P P 2$-and $R P P 4$-derived signals. The finding that the expression of AtWRKY54 is undetectable in the nahG transgenic line after inoculation with $P$. parasitica Cala2 and therefore is not specific for the SA-independent RPP2-mediated signaling pathway supports this idea. Thus, this member was selected for further analysis. AtWRKY54 consists of three exons and two introns, the last intron being located within the region coding for the WRKY domain. To find out if AtWRKY54 is required for the tested resistance responses, affects the expression of other group III members, or both, an AtWRKY54 insertion mutant was identified in the ZIGIA lines (Wisman et al. 1998). The mutant contains a 2.6$\mathrm{kb}$ fragment of the originally 8.1-kb En-1 transposon from Zea mays inserted in the first exon of AtWRKY54. The first three base pairs of the insertion lead to a premature stop codon at position 78 in the predicted amino acid sequence of AtWRKY54, thus generating a truncated protein (Fig. 6). The truncated protein does not contain the DNA-binding WRKY domain. Therefore, the homozygous insertion line was assumed to be a loss of function mutant. Under short and long day conditions, this line did not show any obviously altered phenotype when compared with wild-type plants. After inoculation with $P$. parasitica Emoy2 and Cala2 or B. graminis f. sp. hordei, the resistance in the insertion mutant was also not affected (data not shown), suggesting that AtWRKY54 is not alone crucial for resistance against these pathogens. However, lack of AtWRKY54 expression clearly affected the expression kinetics of several other WRKY group III genes, including AtWRKY38, AtWRKY62, AtWRKY53, and AtWRKY70, upon treatment with SA (Fig. 7B). Unlike the transient expression pattern seen in wild-type plants, these genes showed a sustained expression $24 \mathrm{~h}$ after stimulus application, indicating that WRKY gene expression is directly or indirectly interconnected.

\section{Analysis of the $5^{\prime}$ noncoding region of AtWRKY54.}

Induced AtWRKY54 expression was more rapid upon treatment with SA than was observed following inoculation with $P$. parasitica Cala2 (Figs. 2 and 4A). We performed an analysis of the promoter sequence to identify potential cis-acting elements responsible for its induction upon these two stimuli. Using the PLACE database (Higo et al. 1999), $1.5 \mathrm{~kb}$ of the noncoding 5' flanking sequence were searched for previously identified cis regulatory elements known to mediate expression of defense-related genes. Two $\mathrm{W}$ boxes, the binding sites for WRKY factors, were identified at a distance of -481 and -537 bp upstream of the transcription start site. One of the identified $\mathrm{W}$ boxes is part of an elicitor responsive element known from the CHN50 promoter (Fukuda 1997). With the exception of additional $\mathrm{W}$ box TGAC core sequences, no other previously identified elements, such as GCC boxes (Ohme-Tagaki et al. 2000) or SA-responsive $a s-1$ elements (Qin et al. 1994), were identified. To test whether regions containing the identified $\mathrm{W}$ boxes are important for the response to pathogens or SA, transgenic plants containing different length AtWRKY54 promoter::GUS reporter gene constructs were generated (Fig. 6A). The T2 generation of stable transformants were tested for the induction of the reporter gene after spraying with $5 \mathrm{mM} \mathrm{SA}$ or upon inoculation with $P$. parasitica Cala2, respectively. Repre- 
sentative results from the analysis of at least five independent transgenic lines for each construct are shown in Figure 7B.

All three promoter versions allow expression of the reporter gene after treatment with SA. In contrast, only the -694 promoter construct is capable of inducing the reporter gene upon inoculation with $P$. parasitica Cala2. These results demonstrate that different regions within the $5^{\prime}$ regulatory sequences of AtWRKY54 are responsible for $\mathrm{SA}$ and pathogen responsive gene expression.

A

Mock

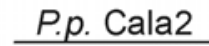

[h] $0 \longdiv { 2 4 4 6 2 4 4 8 7 2 } \overline { 2 4 6 2 4 4 8 7 2 }$

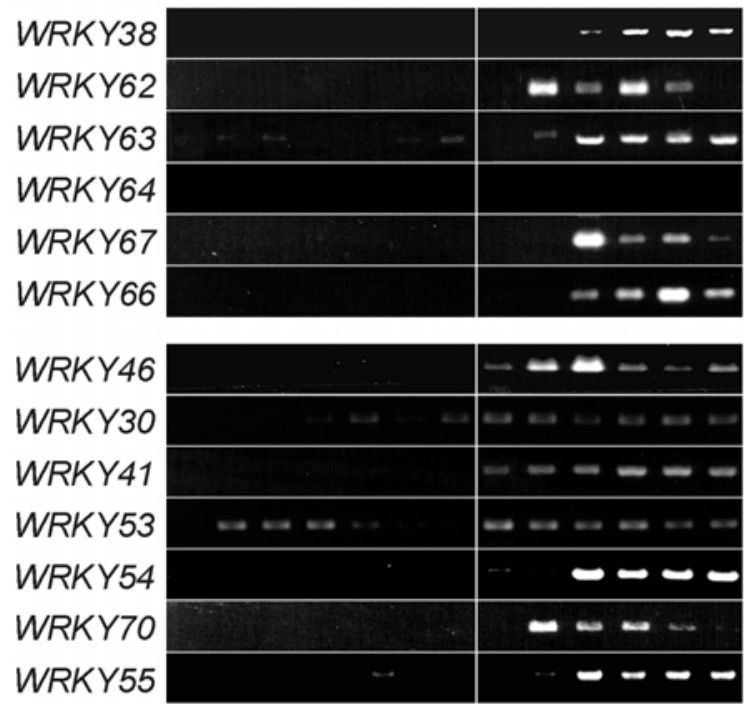

Actin

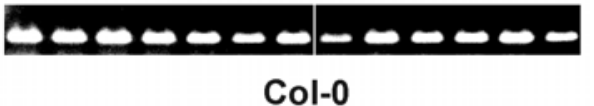

C
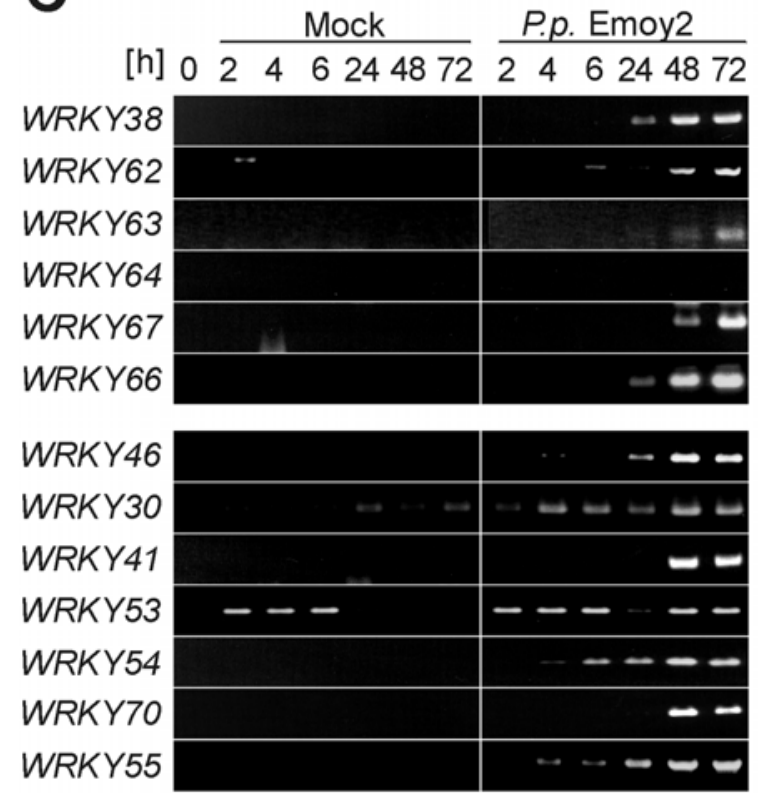

Actin

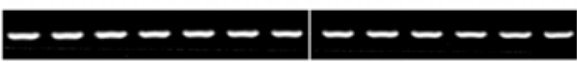

Col-0

\section{DISCUSSION}

All 13 WRKY genes from Arabidopsis thaliana coding for transcription factors with the group III specific C2-HC zinc finger motif were chosen for expression analysis during biotic and abiotic stresses. WRKY proteins containing this special motif have previously been cloned from tobacco (Chen and Chen 2000) and parsley (Cormack et al. 2002) and were shown

B

[h] $0 \frac{\text { Mock }}{246244872} \frac{\text { P.p. Cala2 }}{246244872}$
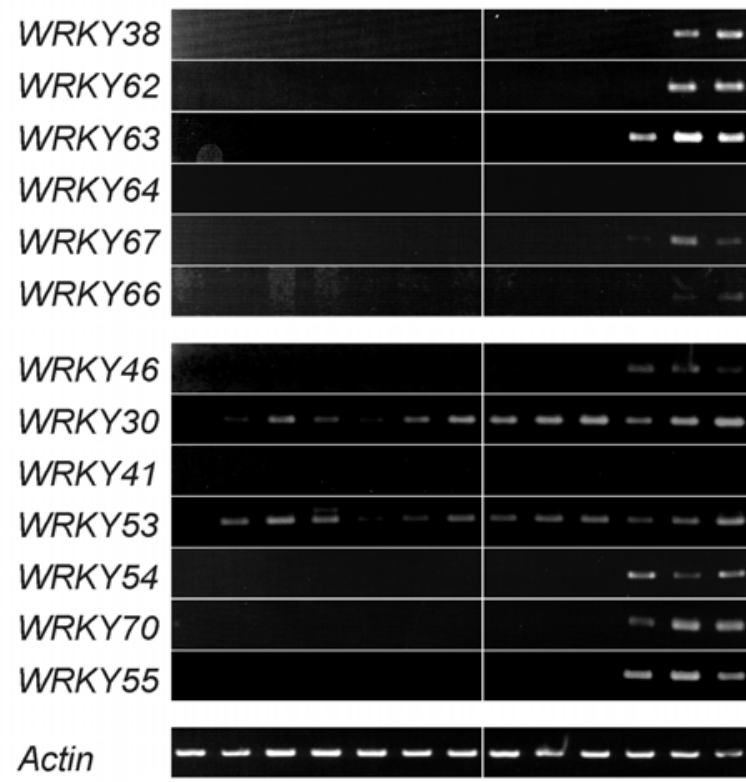

Ler-1

D
[h]

WRKY38

WRKY62

WRKY63

WRKY64

WRKY67

WRKY66

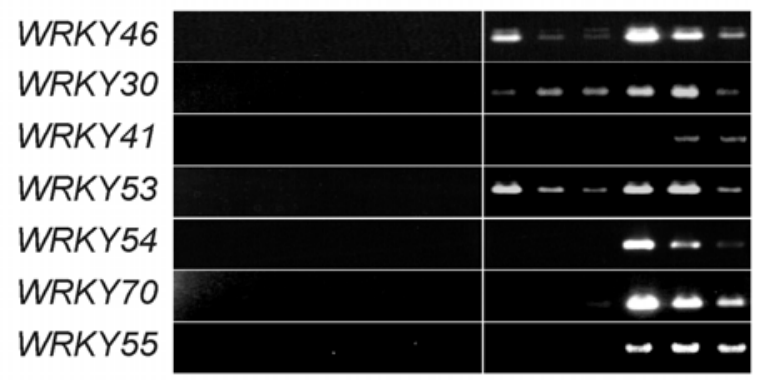

Actin

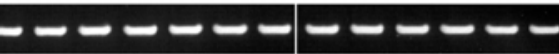

Col-0

Fig. 4. Timecourse expression analysis of WRKY group III genes in Columbia (Col-0) and Landsberg erecta (Ler-1) ecotype Arabidopsis plants upon pathogen challenge. A, Col-0 plants inoculated with Peronospora parasitica (P.p.) Cala2; B, Col-0 plants inoculated with P. parasitica Emoy2; C, Ler-1 plants inoculated with . parasitica Cala2; D, Col-0 plants inoculated with Blumeria graminis (B.g.) f. sp. hordei. Control plants were mock-inoculated with water. 
A

[h] 0 \begin{tabular}{lllll}
2 & \multicolumn{2}{c}{ Mock } & & P.p. Cala2 \\
24 & 6244872 & 246244872
\end{tabular}

\begin{tabular}{|c|c|}
\hline WRKY38 & $\therefore 00$ \\
\hline WRKY62 & $-\infty$ \\
\hline WRKY63 & $x=$ \\
\hline WRKY64 & \\
\hline WRKY 67 & $=0$ \\
\hline WRKY66 & -- \\
\hline
\end{tabular}

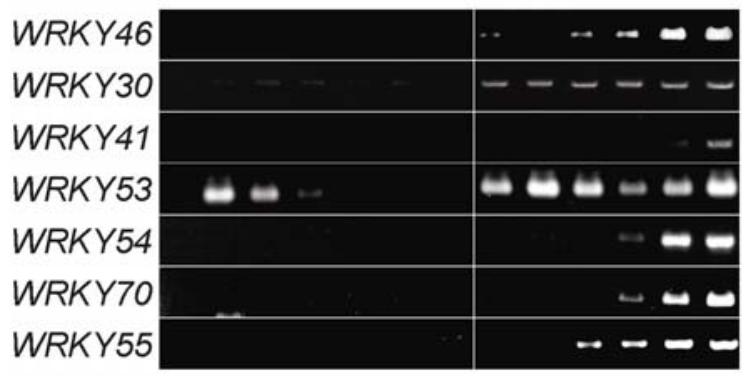

Actin

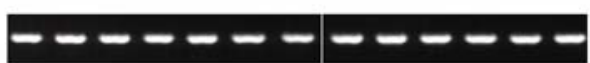

pad4-1

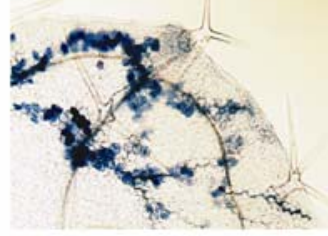

C
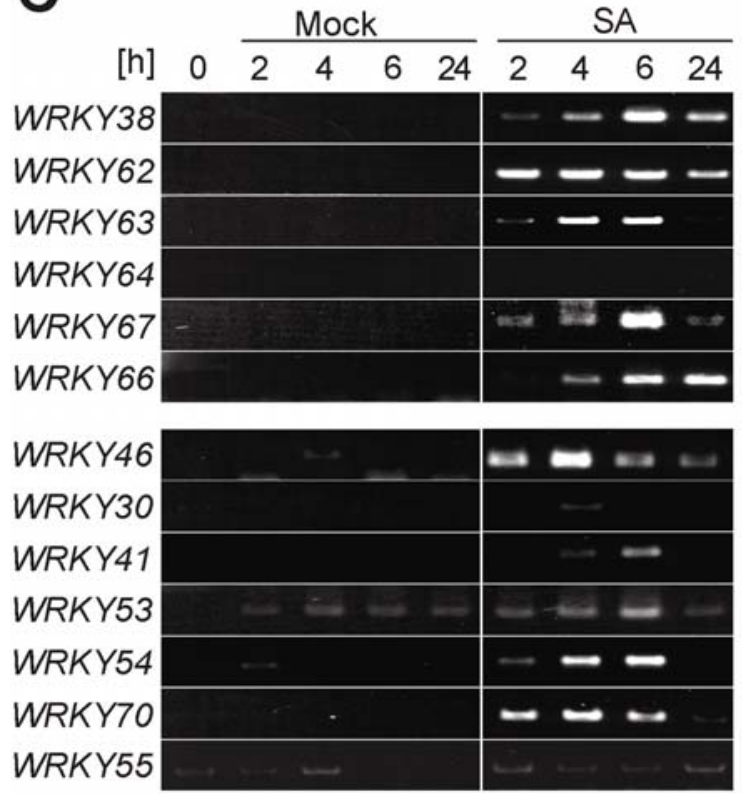

Actin
B
[h] 0 \begin{tabular}{cccc} 
& \multicolumn{1}{c}{ Mock } & & P.p. Cala2 \\
246244872 & 246244872
\end{tabular}
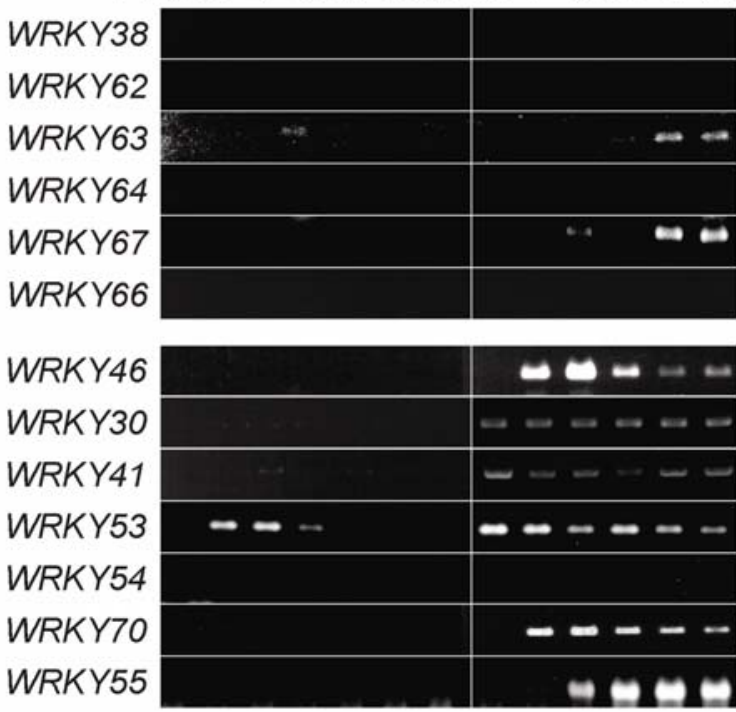

Actin

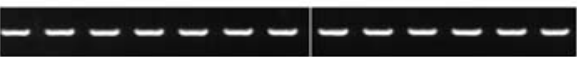

NahG

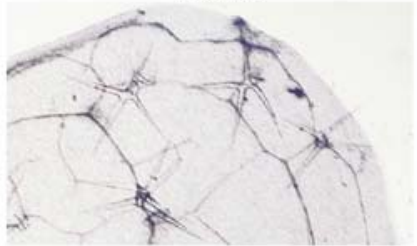


to be able to bind specifically to $\mathrm{W}$ box elements and to activate gene expression. Data concerning WRKY group III genes remains very limited, despite several recent genome-wide expression profile studies dealing with plant defense-related responses (Chen et al. 2002b; Cheong et al. 2002). This is due to the fact that group III WRKY genes are nearly absent from currently used microarrays. Only for AtWRKY53, AtWRKY70, and $A t W R K Y 62$ was altered expression upon pathogen attack, wounding, during leaf senescence, and upon treatment with SA demonstrated (Brodersen et al. 2002; Cheong et al. 2002; Hinderhofer and Zentgraf 2001; Yu et al. 2001).

Figure 8A summarizes the temporal expression patterns we obtained for the WRKY group III genes. Most of the analyzed genes are induced by SA, including AtWRKY53, AtWRKY62 and AtWRKY70, which is consistent with previous reports (Brodersen et al. 2002; Yu et al. 2001). Some of the analyzed genes are induced within $2 \mathrm{~h}$ after treatment with SA and might be regarded as immediate early type WRKY genes (Cormack et al. 2002). This is partly supported by macroarray analyses demonstrating activation of AtWRKY38, AtWRKY46, AtWRKY53, AtWRKY67, and AtWRKY70 transcription in the presence of the protein synthesis blocker cycloheximide ( $\mathrm{R}$. Stracke, I. Somssich, and B. Weißhaar, unpublished data). $W R K Y$ gene induction in pathogen-infected plants occurred generally later than after SA treatment. Possibly, this response requires the release of elicitors from germinating spores, a time-consuming process. Alternatively, germinating pathogens may release substances that temporarily suppress certain mechanisms involved in plant defense activation. However, based on our investigation of one member, namely AtWRKY54, it would appear that the signaling events leading to SA- and pathogen-induced expression are not identical. Analysis of AtWRKY54 promoter::GUS reporter lines revealed that different regions within the $5^{\prime}$ regulatory sequences of AtWRKY54 are responsible for $\mathrm{SA}$ - and pathogen-responsive gene expression. Apart from WRKY-factor binding sites (W boxes), no other elements known to be involved in mediating plant defense gene activation were identified, with the exception of an ElRE sequence, which also contains a functional $\mathrm{W}$ box. Thus, expression of AtWRKY54 upon infection or by SA treatment may require the binding of distinct WRKY factors to their respective $\mathrm{W}$ box elements. Similarly, therefore, association of WRKY factors to different, stimulus-specific regions in the promoters of other WRKY genes might influence their timely variable induction upon diverse biotic and abiotic signals.

The temporal expression of most WRKY group III genes in the compatible interaction $P$. parasitica Cala2/Ler-1 is delayed, compared to the incompatible interaction $P$. parasitica Cala2/Col-0 (Fig. 8A). This is consistent with previous findings demonstrating that timely expression of defense-associated genes is a crucial step during plant defense (Cao et al. 1994). Interestingly, most of the analyzed genes in the incompatible interaction $P$. parasitica Emoy $2 / \mathrm{Col}-0$ showed delayed expression, indicating that the early induction of such genes might be specific for $P$. parasitica Cala 2 and, therefore, to be $R P P 2$ dependent. In contrast, during nonhost resistance, several genes are not expressed at all. This could be explained by the lack of tight coevolution between Arabidopsis and this nonhost pathogen. Neither did the fungus develop specific mechanisms to colonize Arabidopsis plant tissue nor did adapted mechanisms emerge in the plant to recognize $B$. graminis f. sp. hordei-specific elicitors.

By analyzing the expression patterns in different interactions and mutants, it became obvious that distinct subsets of WRKY genes are activated by different queues along defined signal transduction pathways (Fig. 8B). At least four different induc- tion groups can be distinguished. AtWRKY55 and AtWRKY46 are both induced $R P P 2$ dependently but do not require a functional PAD4 for expression upon infection with $P$. parasitica Cala2 and are thus induced prior to PAD4 function. The expression of other genes is dependent on a functional $P A D 4$, such as $A t W R K Y 70$ and AtWRKY41. Although RPP2-mediated resistance is independent of the accumulation of SA, expression of WRKY genes AtWRKY62, AtWRKY66, AtWRKY63, AtWRKY38, AtWRKY67, and AtWRKY54 is delayed in nahG mutants after inoculation with $P$. parasitica Cala2. These genes require accumulation of SA for early induction and are, therefore, not direct targets of $R P P 2$ signaling but are, rather, secondarily induced by subsequent SA accumulation. The fourth group, including AtWRKY3O and AtWRKY53, is induced independently of RPP2- and RPP4-specific signals. AtWRKY53 has previously been shown to be rapidly but only transiently induced upon wounding (Chen et al. 2002b). This is consistent with our data showing elevated transcript levels in water-

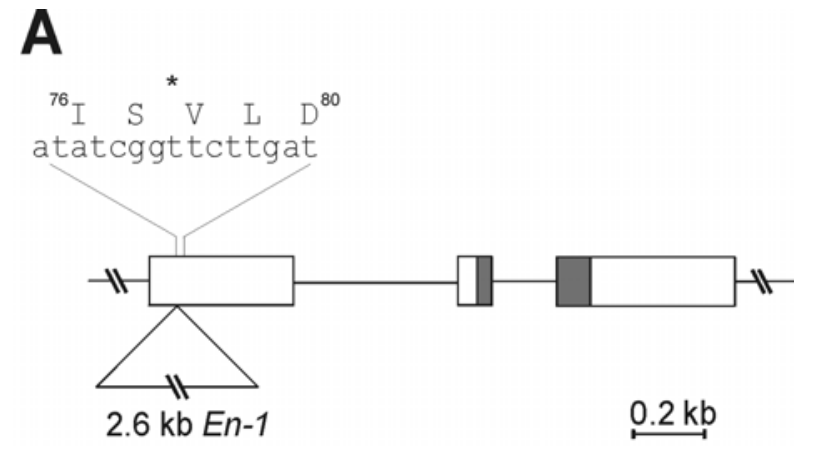

B
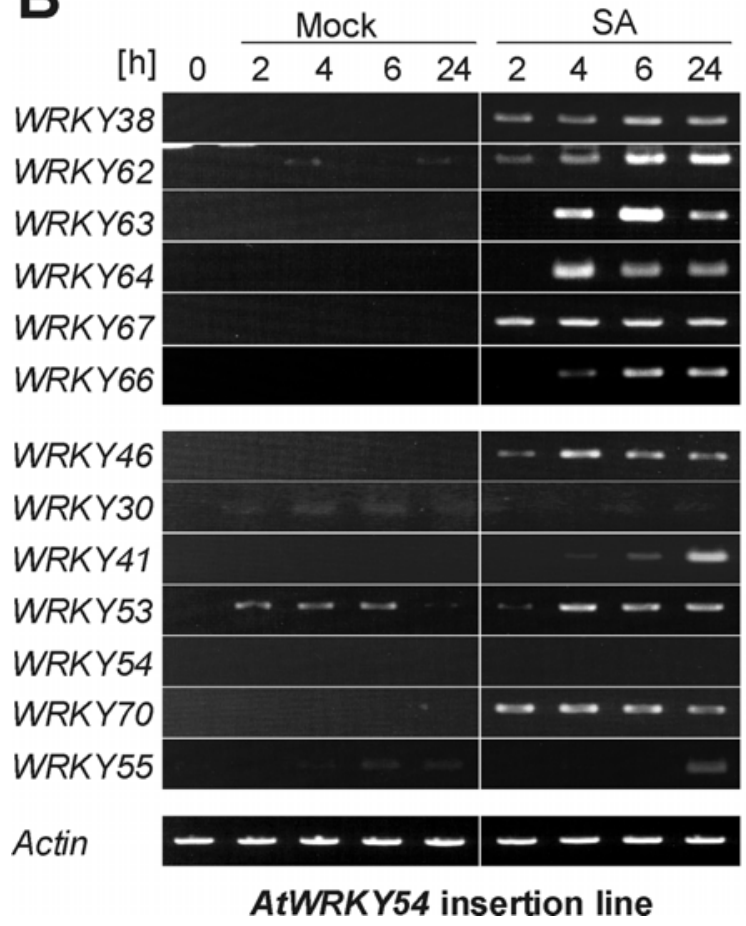

Fig. 6. AtWRKY54 transposon insertion mutant line. A, Schematic representation of the AtWRKY54 gene. The gene is comprised of three exons (boxes) and two introns. Grey boxes indicate the region encoding the WRKY domain. The position of the $E n-1$ in the insertion line is indicated by a triangle. The AtWRKY54 gene sequence at the En-1 integration site is shown above. The En-1 insertion leads to a premature stop codon, marked by an asterisk above the putative amino acid sequence after amino acid position 78. B, Expression of WRKY group III genes in the AtWRKY54 mutant line after spraying with $5 \mathrm{mM}$ salicylic acid. 
A

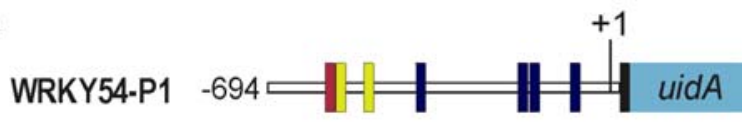

WRKY54-P2

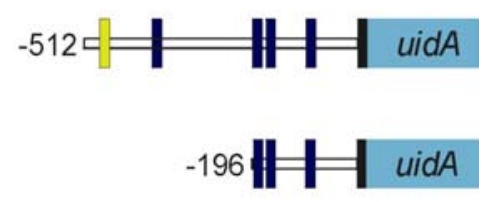

WRKY54-P3

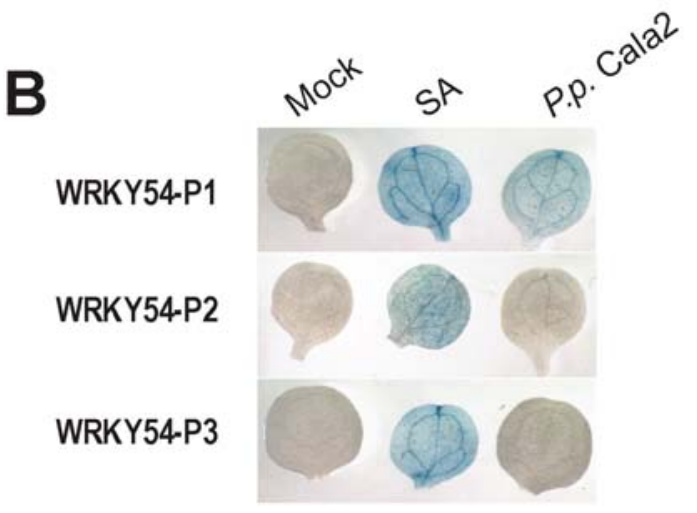

Fig. 7. Analysis of AtWRKY54 promoter::GUS transgenic Arabidopsis lines. A, Schematic representation of AtWRKY54 promoter::reporter gene constructs. The uidA gene is inserted downstream of the first $30 \mathrm{bp}$ of AtWRKY54 exon 1 (black box). Colored boxes indicate positions of previously described cis acting elements in the $5^{\prime}$ regulatory region. Blue boxes represent the invariant TGAC W box core sequence (Eulgem et al. 2000), yellow boxes represent known functional W box motifs (Eulgem et al. 1999; Yu et al. 2001). The red box represents the elicitor responsive cis element GGTCANNNAGTC, previously identified in the CHN50 promoter of tobacco (Fukuda 1997). Numbers on the left indicate the length of the $5^{\prime}$ regulatory sequence of each construct. +1 denotes determined transcriptional start site. B, GUS reporter gene activity observed in the indicated transgenic lines after treatment with salicylic acid (SA) and Peronospora parasitica (P.p.) Cala2. Mock control leaves were sprayed with water.

sprayed control plants. Nevertheless, this transient wound response is generally diminished after $24 \mathrm{~h}$ and, thus, only partly overlaps with the induction kinetics observed upon pathogen or SA treatments. The differential expression of $W R K Y$ genes at several distinct levels in the complex signal transduction network suggests that different WRKY factors may have discernible functions at various steps of the signaling cascade. Possibly, it is this concerted interplay of involved factors which ultimately results in the activation of the complete plant stress response. Recently, SA-dependent and SA-independent activation of distinct WRKY genes was also demonstrated in tobacco following tobacco mosaic virus infection (Yoda et al. 2002).

The described four induction groups do not mirror phylogenetic relationships. Instead, their expression patterns are not predictable from their amino acid sequences. Two of the most closely related proteins in WRKY group III are $A t$ WRKY70 and AtWRKY54. AtWRKY70 has previously been demonstrated to be strongly induced in the acd11 mutant (Brodersen et al. 2002) and, therefore, is most likely to be involved in the hypersensitive cell-death response, whereas expression of AtWRKY54 was not observed. Recent group-wide analysis of other gene families, like the AtCMPG, glutamate-receptor-like gene family or the AtHVA22 gene family (Chen et al. 2002a; Chiu et al. 2002; Heise et al. 2002), revealed that a similar primary structure does not necessarily correlate with a similar gene regulatory response. Still, despite their different regulation, similar physiological roles of these proteins cannot be excluded.

We assume that the large number of WRKY factors involved in plant defense helps to orchestrate a broad and spatially controlled response. The apparent loss of the transient expression kinetics for several WRKY genes observed in the AtWRKY54 mutant hints toward an intricate interconnected signaling network in which WRKY factors are involved in integrating diverse stress stimuli. In such a scenario, the loss of one function directly or indirectly affects the temporal and perhaps also the spatial expression of numerous other genes. However, as with AtWRKY54 here and from previous studies (Robatzek and Somssich 2002), single WRKY knockouts do not result in obvious altered phenotypes. Thus, functional redundancy must exist between different WRKY factors. In fact, in only one reported instance has the disruption of a single WRKY gene resulted in an altered phenotype. Interestingly, expression of this gene, TTG2, which corresponds to AtWRKY44, is not influenced by pathogens nor by various abiotic stresses (Chen et al. 2002b) but rather is involved in trichome and seed coat development (Johnson et al. 2002).

Currently 39 out of the 74 Arabidopsis WRKY genes have been shown to respond to different biotic and abiotic stresses. Still, the functions of these transcription factors are not restricted to plant defense. Instead, they are involved in numerous processes required for diverse plant functions, such as proper development (Johnson et al. 2002), embryogenesis (Alexandrova and Conger 2002), dormancy and drought tolerance (Pnueli et al. 2002), and also thermal hysteresis (Huang and Duman 2002). It is most likely that the involvement of WRKY factors in these diverse processes is as complex as that during plant defense. Defining the role of individual members remains a great challenge for future work. Whole-genome expression profile analysis, particularly in combination with various other signaling mutants and with knockout mutants for all WRKY genes, will certainly be useful in this respect. Such studies will help to reveal how interwoven signaling networks are and should provide valuable information how, within such networks, WRKY factors contribute to maintain proper plant health and development.

\section{MATERIALS AND METHODS}

\section{Plant material and growth conditions.}

Experiments were performed with Arabidopsis thaliana ecotype Columbia (Col-0) and Landsberg erecta (Ler-1). The nahG and pad4-1 mutants were described previously (Gaffney et al. 1993; Glazebrook et al. 1997). Approximately 200 plants per pot were grown in a phytochamber (Percival Scientific, Boone, IA, U.S.A.) at 20 to $22^{\circ} \mathrm{C}$ under short day conditions (9 to $10 \mathrm{~h}$ light, 14 to $15 \mathrm{~h}$ darkness); 12 - to 14 -day-old plants were used for experiments.

\section{Inoculation with fungal strains and treatment with SA.}

Fungal strains Peronospora parasitica Emoy2 and Cala2 were supplied by E. Holub (Horticulture Research International, East Malling, U.K.). The fungus B. graminis f. sp. hor$d e i$ was provided by V. Lipka (MPIZ, Köln, Germany). Pathogen challenge inoculations were conducted by spraying the seedlings with a $P$. parasitica spore suspension $\left(10^{5}\right.$ spores $\left.\mathrm{ml}^{-1}\right)$ or by dispersing spores of $B$. graminis f. sp. hordei on the leaves. Plants infected with $P$. parasitica were incubated under $100 \%$ relative humidity. Control plants were treated equally but not infected with fungal spores. For SA treatment, plants were sprayed with $5 \mathrm{mM}$ SA until wet and were incubated similarly to $P$. parasitica-infected plants. As mock control, 


\begin{tabular}{|c|c|c|c|c|c|c|c|c|c|}
\hline \multirow{2}{*}{$\begin{array}{l}\text { A } \\
\text { WRKY }\end{array}$} & \multirow[b]{2}{*}{$\begin{array}{c}\mathrm{SA} \\
\text { induced }\end{array}$} & \multirow[b]{2}{*}{$\begin{array}{c}\text { SA- } \\
\text { dependent }\end{array}$} & \multicolumn{4}{|c|}{ temporal expression in: } & \multirow[b]{2}{*}{$\begin{array}{l}\text { B.g.hordei/ } \\
\text { Col-0 }\end{array}$} & \\
\hline & & & $\begin{array}{r}\text { Cala2/ } \\
\text { Col-0 } \\
\end{array}$ & $\begin{array}{c}\text { Cala2/ } \\
\text { Ler-1 }\end{array}$ & $\begin{array}{c}\text { Emoy2/ } \\
\text { Col-0 }\end{array}$ & $\begin{array}{l}\text { Cala2/ } \\
\text { pad4-1 }\end{array}$ & & 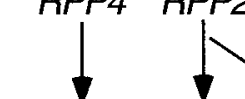 & 55 \\
\hline 30 & no & no & early & early & early & early & yes & PAD4 & 46 \\
\hline 55 & no & no & early & delayed & early & early & yes & 11 & 30,5 \\
\hline 66 & yes & yes & early & delayed & delayed & delayed & yes & i & $\boldsymbol{7}$ \\
\hline 62 & yes & partly & early & delayed & delayed & delayed & no & 1 & \\
\hline 63 & yes & partly & early & delayed & delayed & delayed & no & & 70,41 \\
\hline 64 & yes & no & no & & no & no & no & $c \wedge$ & $64 *$ \\
\hline 38 & yes & yes & early & delayed & delayed & delayed & yes & $S A$ & \\
\hline 67 & yes & yes & early & delayed & delayed & delayed & yes & & \\
\hline 54 & yes & yes & early & delayed & early & delayed & yes & & 66.62 \\
\hline 70 & yes & no & early & delayed & delayed & delayed & yes & & $\begin{array}{l}00,0<, \\
6338\end{array}$ \\
\hline 46 & yes & no & early & delayed & delayed & early & yes & & 03,38, \\
\hline 41 & yes & no & early & delayed & delayed & delayed & yes & $1 \quad 1$ & $67,54+$ \\
\hline 53 & yes & no & early & early & early & early & yes & Resistance & \\
\hline
\end{tabular}

Fig. 8. Summary of the $W R K Y$ gene expression patterns observed in this study and integration of the data into the $R P P$-dependent signaling pathways. A, Early $W R K Y$ expression is defined as detectable 2 to $6 \mathrm{~h}$ postinoculation, whereas delayed expression is detectable 24 to $72 \mathrm{~h}$ postinoculation. B, $P A D 4$ (boxed) encodes a lipase-like protein and has been shown to be a key player in the RPP2/4 defense signaling pathway (van der Biezen et al. 2002). Question mark indicates an unknown pathway not dependent on RPP2/4 or PAD4. Open arrows point towards those group III WRKY members whose expression is induced at that hierarchical level along the pathway.

other plants were sprayed with deionized water. RNA was isolated at different times after treatment with SA or fungal infection. For RNA analysis, leaf material was harvested at the indicated timepoints, frozen in liquid $\mathrm{N}_{2}$, and stored at $-70^{\circ} \mathrm{C}$. Development of $P$. parasitica inside leaves was monitored by boiling fresh leaves for $3 \mathrm{~min}$ with lactophenol-trypan blue, destaining in chloral hydrate overnight, and examination in $70 \%$ glycerol under a light microscope.

\section{RNA analysis.}

Plant material was ground in liquid $\mathrm{N}_{2}$, and RNA was isolated using either RNA/DNA Maxi Kit (Qiagen, Hilden, Germany) or TRIZOL-reagent (Invitrogen, Karlsruhe, Germany) according to the manufacturer's instructions. RNA was quantified by UV-spectrometry, and $20 \mu \mathrm{g}$ was used for RNA blot analysis. RT-PCR was performed using either the OneStep RT-PCR kit (Qiagen) and gene specific primers or Superscript reverse transcriptase (Invitrogen, Karlsruhe, Germany) with Oligo( $\left.\mathrm{dT}_{12-18}\right)$ primers (Amersham Pharmacia, Freiburg, Germany) and subsequent PCR reaction with gene specific primers. Depending on the WRKY gene, amounts of $5 \mathrm{ng}$ to $0.5 \mu \mathrm{g}$ RNA (exception: $2 \mu \mathrm{g}$ for AtWRKY41) were used, and 25 to 35 cycles were performed for each reaction. Preliminary experiments verified that PCR conditions were not saturated. For quantification, the PCR-amplified products were separated on agarose gels.

\section{Transgenic plants.}

AtWRKY54 promoter::GUS reporter gene constructs containing either the -694-, -512-, or -196-bp promoter fragment, the 138 bp containing the $5^{\prime}$ untranslated region, and the first 10 codons were fused in-frame with the uidA gene (Fig. 6A) in the binary Ti vector pGPTV (Becker et al. 1992). Plants were transformed using the floral-dip method (Clough and Bent 1998), Agrobacterium tumefaciens GV3101. Seeds from transformed plants were surface-sterilized and were germinated on $0.6 \%$ agar plates containing kanamycin. Plants from the T2 generation were analyzed for $\beta$-glucuronidase (GUS) expression, as described previously (Jefferson et al. 1987), $24 \mathrm{~h}$ after the different treatments.

\section{ACKNOWLEDGMENTS}

We are grateful to P. Schulze-Lefert and K. Hahlbrock for valuable discussions and continuous support, D. Wanke for help with the phylogenetic analyses, S. Dorweiler for plant maintenance, S. Heppelmann, N. Schmitz, and N. Kamphaus for skilful technical assistance, and M. Krehenbrink for the critical reading of the manuscript.

\section{LITERATURE CITED}

Alexandrova, K. S., and Conger, B. V. 2002. Isolation of two somatic embryogenesis-related genes from orchardgrass (Dactylis glomerata). Plant Sci. 162:301-307.

Asai, T., Tena, G., Plotnikova, J., Willmann, M. R., Chiu, W.-L., GomezGomez, L., Boller, T., Ausubel, F. M., and Sheen, J. 2002. MAP kinase signalling cascade in Arabidopsis innate immunity. Nature 415:977983.

Back, K., and Chappell, J. 1996. Identifying functional domains within terpene cyclases using a domain-swapping strategy. Proc. Natl. Acad. Sci. U.S.A. 93:6841-6845.

Bailey, T. L., and Elkan, C. 1994. Fitting a mixture model by expectation maximization to discover motifs in biopolymers. Pages 28-36 in: Proceedings of the Second International Conference on Intelligent Systems for Molecular Biology. American Association for Artificial Intelligence Press, Menlo Park, CA, U.S.A.

Bailey, T. L., and Gribskov, M. 1998. Combining evidence using pvalues: Application to sequence homology searches. Bioinformatics $14: 48-54$

Becker, D., Kemper, E., Schell, J., and Masterson, R. 1992. New plant binary vector with selectable markers located proximal to the left T-DNA border. Plant Mol. Biol. 20:1195-1197.

Brodersen, P., Petersen, M., Pike, H. M., Olszak, B., Skov, S., Ødum, N., Jørgensen, L. B., Brown, R. E., and Mundy, J. 2002. Knockout of Arabidopsis ACCELERATED-CELL-DEATH11 encoding a sphingosine transfer protein causes activation of programmed cell death and defense. Genes Dev. 16:490-502.

Cao, H., Bowling, S. A., Gordon, S. A., and Dong, X. 1994. Characterization of an Arabidopsis mutant that is nonresponsive to inducers of systemic acquired resistance. Plant Cell 6:1583-1592. 
Chen, C., and Chen, Z. 2002. Potentiation of developmentally regulated plant defense response by AtWRKY18, a pathogen-induced Arabidopsis transcription factor. Plant Physiol. 129:706-716.

Chen, C., and Chen, Z. 2000. Isolation and characterization of two pathogen- and salicylic acid-induced genes encoding WRKY DNA-binding proteins from tobacco. Plant Mol. Biol. 42:387-396.

Chen, C.-N., Chu, C.-C., Zentella, R., Pan, S.-M., and Ho, T.-H.D. 2002a. AtHVA22 gene family in Arabidopsis: Phylogenetic relationship, ABA and stress regulation, and tissue-specific expression. Plant Mol. Biol. 49:633-644.

Chen, W. Provart, N. J., Glazebrook, J., Katagiri, F., Chang, H.-S., Eulgem, T., Mauch, F., Luan, S., Zou, G., Whitham, S. A., Budworth, P. R. Tao, Y., Xie, Z., Chen, X., Lam, S., Kreps, J. A., Harper, J. F., SiAmmour, A., Mauch-Mani, B., Heinlein, M., Kobayashi, K., Hohn, T., Dangl, J. L., Wang, X., and Zhu, T. 2002b. Expression profile matrix of Arabidopsis transcription factor genes suggests their putative functions in response to environmental stresses. Plant Cell 14:559-574.

Cheong, Y. H., Chang, H.-S., Gupta, R., Wang, X., Zhu, T., and Luan, S 2002. Transcriptional profiling reveals novel interactions between wounding, pathogen, abiotic stress, and hormonal responses in Arabidopsis. Plant Physiol. 129:661-677.

Chiu, J. C., Brenner, E. D., DeSalle, R., Nitabach, M. N., Holmes, T. C., and Coruzzi, G. M. 2002. Phylogenetic and expression analysis of the glutamate-receptor-like gene family in Arabidopsis thaliana. Mol. Biol. Evol. 19:1066-1082.

Clough, S. J., and Bent, A. F. 1998. Floral dip: A simplified method for Agrobacterium-mediated transformation of Arabidopsis thaliana. Plant J. 16:735-743.

Cormack, R. S., Eulgem, T., Rushton, P. J., Köchner, P., Hahlbrock, K., and Somssich, I. E. 2002. Leucine zipper containing WRKY proteins widen the spectrum of immediate early elicitor-induced WRKY transcription factors in parsley. Biochim. Biophys. Acta 1576:92-100.

de Pater, S., Greco, V., Pham, K., Memelink, J., and Kijne, J. 1996. Characterization of a zinc-dependent transcriptional activator from Arabidopsis. Nucleic Acids Res. 24:4624-4631.

Delaney, T., Uknes, S., Vernooij, B., Friedrich, L., Weymann, K. Negrotto, D., Gaffney, T., Gut-Rella, M., Kessmann, H., Ward, E., and Ryals, J. 1994. A central role of salicylic acid in plant disease resistance. Science 266:1247-1250.

Dellagi, A., Heilbronn, J., Avrova, A. O., Montesano, M., Palva, E. T., Stewart, H. E., Toth, I. K., Cooke, D. E. L., Lyon, G. D., and Birch, P. R. J. 2000. A potato gene encoding a WRKY-like transcription factor is induced in interactions with Erwinia carotovora subsp. atroseptica and Phytophthora infestans and is coregulated with class I endochitinase expression. Mol. Plant-Microbe Interact. 13:1092-1101.

Deslandes, L., Olivier, J., Theulières, T., Hirsch, J., Feng, D. X., BittnerEddy, P., Beynon, J., and Marco, Y. 2002. Resistance to Ralstonia solanacearum in Arabidopsis thaliana is conferred by the recessive $R R S 1-R$ gene, a member of a novel family of resistance genes. Proc. Natl. Acad. Sci. U.S.A. 99:2404-2409.

Du, L., and Chen, Z. 2000. Identification of genes encoding receptor-like protein kinases as possible targets of pathogen- and salicylic acidinduced WRKY DNA-binding proteins in Arabidopsis. Plant J. 24:837-847.

Eulgem, T., Rushton, P. J., Schmelzer, E., Hahlbrock, K., and Somssich, I. E. 1999. Early nuclear events in plant defense: Rapid gene activation by WRKY transcription factors. EMBO (Eur. Mol. Biol. Organ.) J. 18:4689-4699.

Eulgem, T., Rushton, P. J., Robatzek, S., and Somssich, I. E. 2000. The WRKY superfamily of plant transcription factors. Trends Plant Sci. 5:199-206.

Fukuda, Y. 1997. Interaction of tobacco nuclear proteins with an elicitorresponsive element in the promoter of a basic class I chitinase gene. Plant Mol. Biol. 34:81-87.

Gaffney, T., Friedrich, L., Vernooij, B., Negrotto, D., Nye, G., Uknes, S., Ward, E., Kessmann, H., and Ryals, J. 1993. Requirement of salicylic acid for the induction of systemic acquired resistance. Science 261:754-756.

Glazebrook, J. 2001. Genes controlling expression of defense responses in Arabidopsis-2001 status. Curr. Opin. Plant Biol. 4:301-308.

Glazebrook, J., and Ausubel, F. M. 1994. Isolation of phytoalexin-deficient mutants of Arabidopsis thaliana and characterization of their interactions with bacterial pathogens. Proc. Natl. Acad. Sci. U.S.A. 91:8955-8959.

Glazebrook, J., Zook, M., Mert, F., Kagan, I., Rogers, E. E., Crute, I. R., Holub, E. B., Hammerschmidt, R., and Ausubel, F. M. 1997. Phytoalexin-deficient mutants of Arabidopsis reveal that PAD4 encodes a regulatory factor and that four $P A D$ genes contribute to downy mildew resistance. Genetics 146:381-392.
Gu, Q., Kawata, E. E., Morse, M. J., Wu, H. M., and Cheung, A. Y. 1992. A flower-specific cDNA encoding a novel thionin in tobacco. Mol. Gen. Genet. 234:89-96.

Heath, M. C. 2000. Nonhost resistance and nonspecific plant defenses. Curr. Opin. Plant Biol. 3:315-319.

Heise, A., Lippok, B., Kirsch, C., and Hahlbrock, K. 2002. Two immediate-early pathogen-responsive members of the AtCMPG gene family in Arabidopsis thaliana and the W-box-containing elicitor-response element of AtCMPG1. Proc. Natl. Acad. Sci. U.S.A. 99:9049-9054

Higo, K., Ugawa, Y., Iwamoto, M., and Korenaga, T. 1999. Plant cisacting regulatory DNA elements (PLACE) database. Nucleic Acids Res. 27:297-300.

Hinderhofer, K., and Zentgraf, U. 2001. Identification of a transcription factor specifically expressed at the onset of leaf senescence. Planta 213:469-473.

Huang, T., and Duman, J. G. 2002. Cloning and characterization of a thermal hysteresis (antifreeze) protein with DNA-binding activity from winter bittersweet nightshade, Solanum dulcamara. Plant Mol. Biol. 48:339-350.

Ishiguro, S., and Nakamura, K. 1994. Characterization of a cDNA encoding a novel DNA-binding protein, SPF1, that recognizes SP8 sequences in the $5^{\prime}$ upstream regions of genes coding for sporamin and $\beta$-amylase from sweet potato. Mol. Gen. Genet. 244:563-571.

Jefferson, R. A., Kavanagh, T. A., and Bevan, M. W. 1987. GUS fusions: $\beta$-glucuronidase a sensitive and versatile gene fusion marker in higher plants. EMBO (Eur. Mol. Biol. Organ.) J. 6:3901-3907.

Johnson, C. S., Kolevski, B., and Smyth, D. R. 2002. TRANSPARENT TESTA GLABRA2, a trichome and seed coat development gene of Arabidopsis, encodes a WRKY transcription factor. Plant Cell $14: 1359-1375$

Kim, C. Y., Lee, S.-H., Park, H. C., Bae, C. G., Cheong, Y. H., Choi, Y. J., Han, C.-D., Lee, S. Y., Lim, C. O., and Cho, M. J. 2000. Identification of rice blast fungal elicitor-responsive genes by differential display analysis. Mol. Plant-Microbe Interact. 13:470-474.

Maeo, K., Hayashi, S., Kojima-Suzuki, H., Morikami, A., and Nakamura, D. 2001. Role of conserved residues of the WRKY domain in the DNA-binding of tobacco WRKY family proteins. Biosci. Biotechnol. Biochem. 65:2428-2436.

Maleck, K., Levine, A., Eulgem, T., Morgen, A., Schmid, J., Lawton, K. Dangl, J. L., and Dietrich, R. A. 2000. The transcriptome of Arabidopsis thaliana during systemic acquired resistance. Nature Genet. 26:403-410.

McDowell, J. M., Cuzick, A., Can, C., Beynon, J., Dangl, J. L., and Holub, E. B. 2000. Downy mildew (Peronospora parasitica) resistance genes in Arabidopsis vary in functional requirements for NDR1, EDS1, NPR1 and salicylic acid accumulation. Plant J. 22:523-529.

Ohme-Tagaki, M., Suzuki, K., and Shinshi, H. 2000. Regulation of ethylene-induced transcription of defense genes. Plant Cell Physiol. 41:1187-1192.

Ohtake, Y., Takahashi, T., and Komeda, Y. 2000. Salicylic acid induces the expression of a number of receptor-like kinase genes in Arabidopsis thaliana. Plant Cell Physiol. 41:1038-1044.

Page, R. D. M. 1996. TREEVIEW: An application to display phylogenetic trees on personal computers. Computer Applications in the Biosciences 12:357-358.

Pnueli, L., Hallak-Herr, E., Rozenberg, M., Cohen, M., Golouinoff, P., Kaplan, A., and Mittler, R. 2002. Molecular and biochemical mechanisms associated with dormancy and drought tolerance in the desert legume Retama raetam. Plant J. 31:319-330.

Qin, X. F., Holuigue, L., Horvath, D. M., and Chua, N.-H. 1994. Immediate early transcription activation by salicylic acid via the Cauliflower mosaic virus as-1 element. Plant Cell 6:863-874.

Ren, T., Qu, F., and Morris, T. J. 2000. HRT gene function requires interaction between a NAC protein and viral capsid protein to confer resistance to Turnip crinkle virus. Plant Cell 12:1917-1925.

Robatzek, S., and Somssich, I. E. 2002. Targets of AtWRKY6 regulation during plant senescence and pathogen defense. Genes Dev. 16:11391149

Rushton, P. J., Macdonald, H., Huttly, A. K., Lazarus, C. M., and Hooley, R. 1995. Members of a new family of DNA-binding proteins bind to a conserved cis-element in the promoters of $\alpha$-Amy2 genes. Plant Mol. Biol. 29:691-702.

Rushton, P. J., Torres, J. T., Parniske, M., Wernert, P., Hahlbrock, K., and Somssich, I. E. 1996. Interaction of elicitor-induced DNA binding proteins with elicitor response elements in the promoters of parsley PR1 genes. EMBO (Eur. Mol. Biol. Organ.) J. 15:5690-5700.

Thompson, J. D., Higgens, D. G., and Gibson, T. J. 1994. CLUSTAL W: Improving the sensitivity of progressive multiple sequence alignment through sequence weighting, position specific gap penalties and weight 
matrix choice. Nucleic Acids Res. 22:4673-4680.

van der Biezen, E. A., Freddie, C. T., Kahn, K., Parker, J. E., and Jones, J. D. G. 2002. Arabidopsis RPP4 is a member of the RPP5 multigene family of TIR-NB-LRR genes and confers downy mildew resistance through multiple signalling components. Plant J. 29:439-451.

Wang, Z., Yang, P., Fan, B., and Chen, Z. 1998. An oligo selection procedure for identification of sequence-specific DNA-binding activities associated with plant defense. Plant J. 16:515-522.

Wisman, E., Hartmann, U., Sagasser, M., Bauman, E., Palme, K., Hahlbrock, K., Saedler, H., and Weisshaar, B. 1998. Knock-out mutants from an En-1 mutagenized Arabidopsis thaliana population generate phenylpropanoid biosynthesis phenotypes. Proc. Natl. Acad.
Sci. U.S.A. 95:12432-12437.

Yoda, H., Ogawa, M., Yamaguchi, Y., Koizumi, N., Kusano, T., and Sano, H. 2002. Identification of early-responsive genes associated with the hypersensitive response to tobacco mosaic virus and characterization of a WRKY-type transcription factor in tobacco plants. Mol Genet Genomics 267:154-161.

Yu, D., Chen, C., and Chen, Z. 2001. Evidence for an important role of WRKY DNA binding proteins in the regulation of NPR1 gene expression. Plant Cell 13:1527-1539.

Zhou, N., Tootle, T. L., Tsui, F., Klessig, D. F., and Glazebrook, J. 1998. PAD4 functions upstream from salicylic acid to control defense responses in Arabidopsis. Plant Cell 10:1021-1030. 